VET BRIEF

ZOOS' PRINT JOURNAL 20(7): 1934

\section{HELMINTHIASIS IN LEOPARDS (PANTHERA PARDUS) AT BANNERGHATTA BIOLOGICAL PARK}

\section{B.M. Chandranaik ${ }^{1}$, Srinivasa Murthy ${ }^{2}$, Dilip Das ${ }^{3}$, G.S. Mamatha ${ }^{4}$, C. Renukaprasad ${ }^{5}$ and G. Krishnappa ${ }^{6}$}

${ }^{1}$ Scientist 1, ${ }^{5}$ Joint Director, ${ }^{6}$ Director, Institute of Animal Health and Veterinary Biologicals, Hebbal, Bangalore, Karnataka 560024, India ${ }^{4} \mathrm{PhD}$ Scholar, Department of Veterinary Parasitology, Veterinary College, Bangalore, Karnataka 560024, India

${ }^{2}$ Assistant Director, ${ }^{3}$ Veterinarian, Bannerghatta Biological Park, Bannerghatta, Bangalore, Karnataka, India

Available literature provides scanty information on the parasitic diseases, especially helminthiasis in wild felines (Patnaik \& Acharjyo, 1971; Bjork \& Kathe, 2000). Helminthiasis is a chronic problem in captive felines, which attributes to conditions ranging from simple anorexia to gastroenteritis to death of the animal depending on the parasite load and nutritional status of the animal. Present communication elucidates the prevalence of helminthiasis in leopards at Bannerghatta Biological Park (BBP), Bangalore.

Methodology: Eight leopards consisting of three young and five adults, were selected at BBP to study the prevalence of helminthiasis. The present study was carried over a period of one year (Jan. 2003 to Jan. 2004), during which 46 faecal samples were collected and analysed for different parasitic ova and cysts. The faecal samples were collected four times once every three months and few samples were collected randomly one month after each deworming. The samples were collected in clean bags and were processed by sedimentation method as described by Soulsby (1982).

Results and Discussion: On microscopical examination of the 46 faecal samples, 18 samples $(39.1 \%)$ were found positive for the Toxascaris leonina ascarid eggs and 26 (56.5\%) samples were found positive for eggs of Anchylostome sp. of nematodes and $15(32.6 \%)$ samples contained mixed parasitic infections. The samples collected randomly one month after each deworming did not reveal any parasitic eggs, probably due to the action of anthelmentics. During the study it was found that there was not much influence of the season and sex of the animal on the prevalence of these parasitic infections.

Symptoms of occasional diarrhoea, unthriftyness and potbellied appearance were noticed only in two young animals which had mixed infections. Adult leopards, though heavily infested with these parasites, showed no noticeable clinical symptoms except occasional loose stools. Similar finding has been reported by Sengupta (1974).

As these animals were maintained in animal houses where the feeding and drinking places located in the same premises, the contamination of these places with infected faeces is always the main cause of these parasitic infections. This probably indicates a constant and continuous cycle of faeco-oral route of infection, which is further aided by the persistence of the eggs in the environment for a very long time, resulting in maintenance of these parasitic infections. As the faecal samples did not reveal any parasitic eggs after each deworming, a regular deworming schedule with effective drugs like Ivermectin (Meredith \& Beasey, 1991), continuous watch on the hygiene with regular sanitary measures in the animal premises, providing of clean food and water which avoids reinfection, are probably the best ways of prevention and control of these commonly occurring parasitic infections in these animals.

\section{REFERENCES}

Bjork and E. Kathe (2000). Parasites and parasitic stages of free ranging wild lions in N. Tanzania. Journal of Zoo and Wildlife Medicine 31: 56-61.

Meredith, A.L. and A. Beasey (1991). Ivermectin treatment of ascarids in captive Cheetahs. Veterinary Record 129: 241-242.

Patnaik, M. and L.N. Acharjyo (1970). Notes on the helminth parasites of vertebrates in Baranga zoo (Orissa). Indian Veterinary Journal 47: 723.

Sengupta, M.R. (1974). A preliminary report on diseases and parasites of zoo animals, birds and reptiles. Indian Journal of Animal Health June: 16-24.

Soulsby, E.J.L. (1982). Helminths, Arthropods and Protozoans of Domesticated Animals. $7^{\text {th }}$ edition. Baillier Tindall, London.

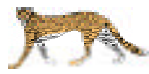

